\title{
On subchromate of lead
}

\section{Wöhler \& Liebig}

To cite this article: MM. Wöhler \& Liebig (1832) On subchromate of lead, Philosophical Magazine Series 2, 11:61, 75-76, DOI: 10.1080/14786443208647680

To link to this article: http://dx.doi.org/10.1080/14786443208647680

册Published online: 25 Jun 2009.

Submit your article to this journal

III Article views: 2

Q View related articles $₫$ 
time, the chloride of magnesium, which is fixed and fusible, flows along the porcelain tube, and solidifies at the end. It is a white crystalline mass, its fracture presents large brilliant plates, it is slightly tlexible, looks like spermaceti, is very soluble in water, has a penetrating bitter taste, and strongly attracts moisture from the air.

To reduce this chloride, M. Bussy takes a rather strong glass tube, about 4-1)ths of an inch interior diameter, and about sixteen inches long, bent at one end like a retort. After introducing five or six fragments of potassium, about the size of a pea, both into the bent and the straight part of the tube, fragments of chloride of magnesium are also put in, placing between them some pieces of porcelain, to prevent the chloride from running into one mass by fusion. This portion of the tube is then heated nearly to dull redness, and the potassium converted into vapour is passed over it, by heating that part of the tube which contains it. Strong ignition ensues, which takes place gradually throughout the tube. When the tube is cold, it is found to contain white metallic globules disseminated throughout the undecomposed chloride. If this mass be treated with water, a disengagement of hydrogen is produced by the action of a small portion of potassium, and white flocks of magnesia are also formed at the same time, derived from the decomposition of a portion of the chloride of magnesium by the potash formed, and brillinnt silvery white globules of magnesium are precipitated to the bottom of the vessel, which are to be repeatedly washed.

Magnesium is very malleable, flattening under the hammer, fusible at a moderate temperature, unalterable in dry air, loses its metallic splendour in moist air, and becomes covered with a white crust of oxide ; this effect is however but limited, and confined to the surface of the metal; when small portions of magnesium are heated in the air, they burn like iron in oxygen, but larger portions are slowly and difficultly converted into pure magnesia : pure water, free from air, has no action on magnesium; when boiling, it gives out some bubbles of hydrogen. Certain saline substances singularly favour the decomposition of water by magnesium; dilute acids attack it with the evolution of hydrogen. Magnesium does not amalgamate directly with mercury without the assistance of heat; a very small quantity of magnesium causes mercury to lose its fluidity.-Ann. de Chimie, xlvi. 434.

\section{ON SUBCHROMATL OF LEAD. BY MM. WÖHLER AND LIEBIG.}

M. Dulong's method of preparing this compound in the moist way is well known. It appears that the product obtained by this process is not of a fine cinnabar red colour: it has merely a deep orange shade, but still fine enough to be employed in dyeing. We have found that, by fusing neutral chromate of lead with nitrate of potash, the subchromate may be obtained of as fine a red as the best cinnabar. The nitre is to be fused at a low red heat, and pure chromate of lead thrown into it in small portions at a time. On each addition of the chromate, strong effervescence occurs, oc- 
casioned by disengagement of gas, and the mass becomes black, because the chrome red, as it may be technically called, appears black when it is hot. The yellow chromate is to be added until all the nitre is decomposed. Care must be taken not to heat the crucible too strongly, because at too high a temperature the colour loses its beauty and becomes brown. The crucible is then to remain for some time, in order that the chrome red, which is heavy, may deposit, and the saline mass, which is composed of chromate of potash and nitre, is to be poured off while fluid. This mass may be used again for the preparation of fresh chromate of lead. The chrome red remaining in the crucible is to be well washed with water, and dried. It is essential not to leave the saline solution long in contact with the red powder; because by this it loses its splendour, and acquires an orange tint. The powder, however, subsides so fast on account of its density and crystalline state, that this inconvenience is easily remedied by increasing the number of washings. The chrome red thus obtained is a powder of a superb cinnabar red colour; when it is examined by the light of the sun, it appears to be composed of small crystalline scales. There is no doubt that it will entirely supersede the use of cinnabar as soon as it can be obtained at a lower price. Yellow chromate of lead dissolves plentifully in a strong boiling solution of potash. After some days this solution deposits groups of red crystals composed of small plates, which consist of subchromate of lead, and of neutral chromate, as has been stated.

PROTOXIDE OF COPPER.

The simplest and easiest method of obtaining protoxide of copper is the following :-Dissolve the copper in muriatic acid, to which small portions of nitric acid are to be added; afterwards evaporate to dryness, and heat the chloride obtained to its fusing point. It is thus converted into brown crystallized chloride. It is afterwards to be fused, ten parts with six of dry carbonate of soda, in a covered crucible at a low red heat. The mass is to be treated with water to dissolve the common salt formed; the protoxide of copper separates in the state of an uncrystalline powder of a fine red colour, which is to be washed and dried.

If muriate of ammonia be added to the above mixture, all the chloride is reduced, as will readily be foreseen, to metallic copper, which separates in a very divided and spongy state, when the mass is dissolved in water.

TITANATE OF IRON.

With the intention of discovering a more convenient method of separating titanic acid from titanate of iron, the mineral well powdered was fused with several times its weight of chloride of calcium in a strong red heat. Chloride of iron constantly escaped between the crucible and the cover, which rendered the weak flame of the charcoal white and brilliant, and deposited upon the sides of the crucible sublimed oxide of iron possessing a metallic lustre. The 